\title{
Stereoselective Synthesis of Substituted Oxocene Cores by Lewis Acid Promoted Cyclization
}

\author{
Arun K. Ghosh ${ }^{\star}$, Anthony J. Tomaine, and Kelsey E. Cantwell \\ Department of Chemistry and Department of Medicinal Chemistry, Purdue University, 560 Oval \\ Drive, West Lafayette, Indiana, 47907, United States
}

\begin{abstract}
Substituted oxocene derivatives have been synthesized by Lewis acid catalyzed reactions of $\varepsilon$ hydroxy-alkene and substituted aromatic aldehydes. The $\mathrm{Cu}(\mathrm{OTf})_{2}$-bis-phosphine catalyzed reaction typically provides substituted dihydropyran derivatives through an olefin-migration, followed by a Prins cyclization. The corresponding reaction catalyzed by TMSOTf or $\mathrm{BF}_{3} \cdot \mathrm{OEt}_{2}$ provided eight-membered cyclic ethers, oxocenes, selectively. This methodology provides convenient access to a variety of 2,4,8-trisubstituted oxocenes in good yields and excellent diastereoselectivities.
\end{abstract}

\section{Graphical Abstract}
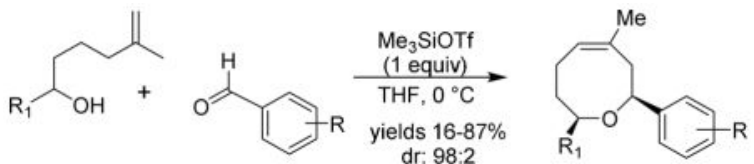

\begin{abstract}
Substituted medium-sized cyclic ethers, particularly eight-membered oxocane and oxocene derivatives, are structural features in a variety of bioactive natural products. ${ }^{1,2}$ This includes, lauthisan (1, Figure 1), helianane (2), laurencin (3), and others. ${ }^{3-6}$ As a result, stereoselective synthesis of these medium-sized oxocyclic rings have been the subject of much interest over the years. ${ }^{7}$ Unlike six-membered ring compounds, construction of eightmembered rings from acyclic precursors is problematic due to factors related to entropy, as well as developing transannular and torsional strains. ${ }^{8,9}$ A number of methods including cycloadditions, ${ }^{10}$ ring expansions, ${ }^{11,12}$ ring-closing metathesis ${ }^{13,14}$ and intramolecular acetal-alkene cyclizations ${ }^{15,16}$ have been developed. A number of these methods were utilized in the synthesis of bioactive molecules. ${ }^{7}$ A majority of these synthetic approaches, however, involve intramolecular reactions, especially in the case of the synthesis of oxocene core structures.
\end{abstract}

An intermolecular reductive cyclization leading to oxocene cores was reported by Solladie and coworkers. ${ }^{17}$ We recently reported that the reaction of substituted alkenol 4 with

\footnotetext{
"Corresponding Authors: akghosh@purdue.edu.

Supporting Information

Experimental procedures and ${ }^{1} \mathrm{H}$ - and ${ }^{13} \mathrm{C}$-NMR spectra are available for all new compounds.
} 
benzyloxyacetaldehyde in the presence of a catalytic amount of $\mathrm{Cu}(\mathrm{OTf})_{2}$ and bis-phosphine complex provided the olefin migration and Prins cyclization product 5 (55\% yield) along with a small amount of eight-membered cyclic ether 6 (11\% yield, Scheme 1). ${ }^{18,19}$ Presumably, the 2,8-substituents in $\mathbf{6}$ are in a cis-relationship, as depicted and the oxocene product was formed by a nucleophilic attack of the olefin onto the oxocarbenium ion $\mathbf{7}$, followed by elimination.

In an effort to access substituted oxocene derivatives, we investigated this reaction with a variety of Lewis acids and reaction conditions. Herein, we report the results of our investigations leading to the synthesis of 2,4,8-trisubstituted oxocenes in a highly diastereoselective manner. We initially investigated the Lewis acid catalyzed cyclization using 6-methylhept-6-en-2-ol (4) and p-nitrobenzaldehyde as the model substrates, as shown in Scheme 2. The use of $10 \mathrm{~mol} \% \mathrm{Sc}(\mathrm{OTf})_{3}$ as the Lewis acid in $\mathrm{CH}_{2} \mathrm{Cl}_{2}$, in the presence of $4 \mathrm{~A}$ molecular sieves at $23{ }^{\circ} \mathrm{C}$, resulted in tetrahydropyran derivative $\mathbf{8}$ as the major product and oxocene derivative $9 \mathrm{a}$ as the minor product in $36 \%$ combined yield. The ratios of products (9a:8) were 9:91 by ${ }^{1} \mathrm{H}-\mathrm{NMR}$ analysis.

With the aim of forming oxocene 9a as the major product directly, we explored a number of oxophilic Lewis acids for this cyclization. Overman and co-workers reported efficient construction of medium sized ring ethers by an intramolecular Prins-type reaction of mixed acetals using $\mathrm{BF}_{3} \cdot \mathrm{OEt}_{2}$ as the Lewis acid in $t$ - $\mathrm{BuOMe}^{20} \mathrm{We}$ first examined the reaction of alkenol 4 with $p$-nitrobenzaldehyde using catalytic amount of $\mathrm{BF}_{3} \cdot \mathrm{OEt}_{2}$ in $\mathrm{CH}_{2} \mathrm{Cl}_{2}$. As it turns out, $\mathrm{BF}_{3} \cdot \mathrm{OEt}_{2}$ catalyzed cyclization provided mainly oxocene product $9 \mathrm{a}$. We have not been able to identify any 6-membered Prins product 8 by ${ }^{1} \mathrm{HNMR}$ analysis of the crude products. The trace amount of minor product appeared to be the exo-olefin product. As shown in Table 1, catalytic amount (20 mol \%) of $\mathrm{BF}_{3} \cdot \mathrm{OEt}_{2}$ in $\mathrm{CH}_{2} \mathrm{Cl}_{2}$ provided $38 \%$ yield of oxocene product $9 \mathbf{a}$ as the major product (entry 2). The use of $40 \mathrm{~mol} \% \mathrm{BF}_{3} \cdot \mathrm{OEt}_{2}$ resulted in a lower yield of oxocene cyclization product $9 \mathbf{a}$ (entry 3 ). The use of $\mathrm{BF}_{3} \cdot \mathrm{OEt}_{2}(3$ equiv) in $t$-BuOMe provided $33 \%$ yield of oxocene product 9a (entry 4). To further improve yields, we then explored TMSOTf in a number of solvent systems. ${ }^{21}$ As it turns out, one equivalent of TMSOTf in a variety of solvents afforded cyclization product, oxocene $\mathbf{9 a}$ as the major product. The choice of diethyl ether in the presence of molecular sieves at $0{ }^{\circ} \mathrm{C}$ for 15 min provided oxocene 9a in 60\% yield (entry 6). The presence of 4A molecular sieves did not improve the yield of oxocene product, but it did improve the endo/exo ratio (entries 5 and 6). The use of toluene resulted in a lower endo/exo ratio. The reaction in DME provided a comparable yield, however, cyclization products were obtained in an 81:19 ratio (entry 8). These ratios were determined based upon ${ }^{1} \mathrm{H}-\mathrm{NMR}$ analysis of the benzylic protons, as the products could not be separated by silica gel chromatography. This Prins-type cyclization provided the best result when THF was used as the solvent in the presence of $4 \mathrm{~A}$ molecular sieves. As shown, oxocene product 9a was obtained essentially as a single product (mixture ratio 98:2) in 73\% isolated yield (entry 9). The reaction in a mixture of $\mathrm{CH}_{2} \mathrm{Cl}_{2}$ and THF also provided comparable yields and mixture ratios (entries 10 and 11). The use of TMSOTf in $t$-BuOMe provided $46 \%$ yield (88:12) of oxocene product $9 \mathbf{a}$ (entry 12).

We then examined the substrate scope of this intermolecular process. As shown in Table 2, a variety of alkyl substituents on the alkyl group of the alkenol substrate were accommodated 
(entries 1-4). The structures of the major endo-products are shown in Figure 2. The electron withdrawing nitro group on the ortho, meta or para-position of the benzene ring of the benzaldehyde provided good yield of oxocene product and excellent endo/exo ratios (entries 5-7). Incorporation of $p-\mathrm{F}, p-\mathrm{CF}_{3}$ or $p$ - $\mathrm{Cl}$ groups provided moderate yields of oxocene derivatives and the endo/exo ratio decreased at the same time (entries 8-10). The reaction with dihydrocinnamaldehyde afforded $35 \%$ yield of oxocene derivative $9 \mathbf{k}$ and endo/exo olefin ratio was 94:6 (entry 11). Also, reaction with benzyloxyacetaldehyde provided oxocene derivative 6 in 24\% yield (entry 12). However, 3-(4-methoxybenzyloxy)propanal and 3-(tert-butyldimethylsilyloxy) propanal failed to provide any oxocene product. The reaction with $m$-methyl or 2-naphthaldehyde provided only $8 \%$ and $16 \%$ yields of the corresponding oxocene derivatives, respectively (entries 13 and 14). The reaction with 4fluoro-3-nitrobenzaldehyde resulted in reduction of yield over the 3-nitrobenzaldehyde (entry 15). This condition was also utilized in the preparation of nearly half a gram quantity of oxocene derivative $9 \mathbf{f}^{22}$

Separation of endo and exo isomers proved difficult by silica gel chromatography or via HPLC methods. In order to confirm the identity of the exo-derivative, we exposed the mixture of products from entry 6 (Table 2) to ozonolytic cleavage at $-78{ }^{\circ} \mathrm{C}$ in a mixture (1:1) of methanol and $\mathrm{CH}_{2} \mathrm{Cl}_{2}$ (Scheme 3). The resulting products were separated by silica gel chromatography. Ketone 12 was then subjected to Wittig olefination with methylene triphenylphosphorane to provide pure exo-olefin derivative 10f. The ${ }^{1} \mathrm{H}-\mathrm{NMR}$ and ${ }^{13} \mathrm{C}-\mathrm{NMR}$ of $10 f$ obtained in this manner matched completely with the minor product in the spectra containing the mixtures.

To determine the X-ray crystal structure, the main product 9a (entry 6) was subjected to reduction with $\mathrm{Zn}$ dust in acetic acid as shown in Scheme $4 .{ }^{23}$ The resulting aromatic amine was reacted with $p$-bromobenzenesulfonyl chloride in the presence of aqueous sodium bicarbonate solution to provide sulfonamide derivative $\mathbf{1 3}$. This was recrystallized from ether/pentane at $23{ }^{\circ} \mathrm{C}$ for $48 \mathrm{~h}$. The single crystal X-ray analysis (Scheme 4) further supports the assignment of cis-stereochemistry. ${ }^{24,25}$

As shown in Table 2, the endo-olefin product was typically the major isomer observed by ${ }^{1} \mathrm{H}$ - and ${ }^{13} \mathrm{C}$-NMR-analysis. The stereochemical assignment of these compounds was carried out by ${ }^{1} \mathrm{H}$ NMR NOESY experiments of compound 9a (Figure 3). The depicted conformation is chosen based upon the X-ray crystal structure. The observed strong NOESY correlation between $\mathrm{H}_{\mathrm{E}}$ and $\mathrm{H}_{\mathrm{D}}$ provided evidence of the assigned cis-relationship between the alkyl and aromatic ring in 9a. Additional NOESY correlations between $\mathrm{H}_{\mathrm{E}}-\mathrm{H}_{\mathrm{C}}, \mathrm{H}_{\mathrm{C}}-\mathrm{H}_{\mathrm{L}}$,

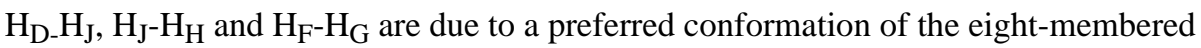
oxocene ring. ${ }^{26}$

The stereochemical outcome of the current Prins-type cyclization, which provided cisoxocene derivatives, can be rationalized based upon the transition-state models in Figure 4. The TMSOTf-catalyzed reactions of alkenol $\mathbf{4}$ and an aromatic aldehyde would lead to the formation of oxocarbenium ion intermediates $\mathbf{1 4 a}$ and $\mathbf{1 4 b}$. 
Subsequent cyclization followed by proton elimination is unlikely to proceed through transiton-state $\mathbf{1 4 b}$ as it shows unfavorable steric interactions. The cyclization is likely to proceed through transition-state 14a leading to cis-product 15a. The formation of transproduct $\mathbf{1 5 b}$ was not observed.

In summary, we have developed an unprecedented TMSOTf-catalyzed intermolecular Prinstype cyclization for the synthesis of a variety of oxocene derivatives. The use of various 1alkyl-5-methylhex-5-en-1-ol and an appropriate aromatic aldehyde afforded a range of oxocene endo olefin derivatives. A stereochemical model also provided explanation for the selective formation of 2,8-cis-oxocene derivatives in up to $87 \%$ yields and excellent diastereoselectivity for disubstituted derivatives. Mechanistic studies and application of these substituted oxocene derivatives are in the progress in our laboratory.

\section{Supplementary Material}

Refer to Web version on PubMed Central for supplementary material.

\section{Acknowledgments}

Financial support by the National Institute of Health is gratefully acknowledged. We thank Dr. Jorden Kass (Purdue University) for preliminary experimental assistance.

\section{References}

1. Majumder KC. RSC Advances. 2011; 1:1152-1170.

2. Faulkner DJ. J Nat Prod Rep. 2002; 19:1-48.

3. Overman LE, Blumenkopf TA, Castaneda A, Thompson AS. J Am Chem Soc. 1986; 108:35163517.

4. Harrison B, Crews P. J Org Chem. 1997; 62:2646-2648. [PubMed: 11671613]

5. Kim G, Sohn TI, Kim D, Paton R. Angew Chem Int Ed. 2004; 53:272-276.

6. Irie T, Suzuki M, Masamune T. Tetrahedron. 1968; 24:4193-4205.

7. Kleinke AS, Webb D, Jamison TF. Tetrahedron. 2012; 68:6999-7018.

8. Kreiter CG, Lehr K, Leyendecker M, Sheldrik WS, Exner R. Chem Ber. 1991; 124:3-12.

9. Illuminati G, Mandolini L. Acc Chem Res. 1981; 14:95-102.

10. Mehta G, Singh V. Chem Rev. 1999; 99:881-930. [PubMed: 11749434]

11. Guyot B, Pornet J, Miginiac L. J Organomet Chem. 1989; 373:279-288.

12. Roxburgh CJ. Tetrahedron. 1993; 49:10749-10784.

13. Maier ME. Angew Chem Int Ed. 2000; 39:2073-2077.

14. Bamford SJ, Goubitz K, van Lingen HL, Luker T, Schenk H, Hiemstra H. J Chem Soc Perkin Trans. 2000; 1:345-351.

15. Blumenkopf TA, Bratz M, Castaneda A, Look GC, Overman LE, Rodriquez D, Thompson AS. J Am Chem Soc. 1990; 112:4386-4399.

16. Blumenkopf TA, Look GC, Overman LE. J Am Chem Soc. 1990; 112:4399-4403.

17. Carreno MC, Des Mazery R, Urbano A, Colobert F, Solladie G. Org Lett. 2005; 7:2039-2042. [PubMed: 15876049]

18. Ghosh AK, Nicponski DR. Org Lett. 2011; 13:4328-4331. [PubMed: 21797234]

19. Ghosh AK, Kass J, Nicponski D, Keyes C. Synthesis. 2012; 44:3579-3589.

20. Bratz M, Bullock WH, Overman LE, Takemoto T. J Am Chem Soc. 1995; 117:5958-5966.

21. Ullapu PR, Kim YS, Lee JK, Pae AN, Kim Y, Min SJ, Cho YS. Chem Asian J. 2011; 6:2092-2100. [PubMed: 21661116] 
22. For experimental details, please see the Supporting Information section.

23. Booth, G. Ullmann's Encyclopedia of Industrial Chemistry. John Wiley \& Sons; New York: 2007. Nitro Compounds, Aromatic.

24. Single-Crystal X-Ray analysis was performed in our X-Ray Crystallography laboratory, Dr. Phil Fanwick, Department of Chemistry, Purdue University, West Lafayette, IN

25. CCDC 1437986 contains the supplementary crystallographic data for Compound 13. This data can be obtained free of charge from The Cambridge Crystallographic Data Centre via www.ccdc.cam.ac.uk/data_request/cif.

26. Rhee HJ, Beom HY, Kim HD. Tetrahedron Lett. 2004; 45:8019-8022. 


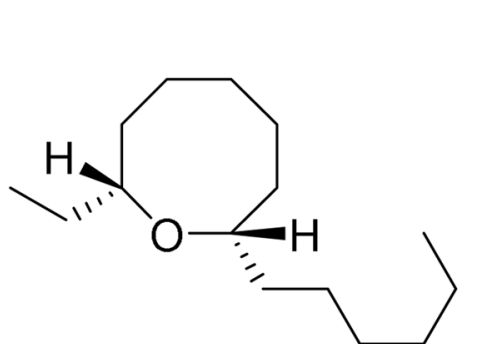

Lauthisan (1)<smiles>Cc1ccc2c(c1)OC(C)(C)CC=C[C@H]2C</smiles>

Helianane (2)

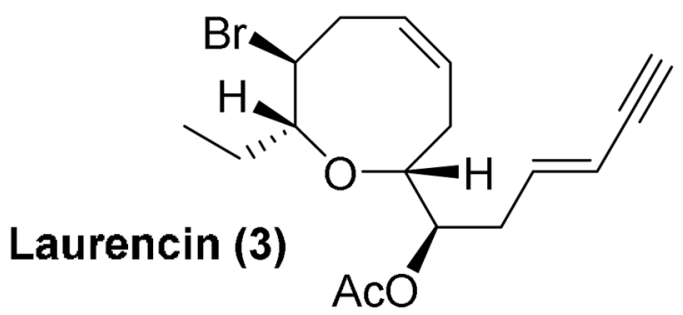

Figure 1.

Structures of oxacyclic natural products 
<smiles>CC1=CCCC(c2ccc([N+](=O)[O-])cc2)OC(c2ccc([N+](=O)[O-])cc2)C1</smiles><smiles>CC1=CCCC(C(C)C)O[C@H](c2ccc([N+](=O)[O-])cc2)C1</smiles><smiles>CC1=CCC[C@@H](C)O[C@H](c2ccccc2[N+](=O)[O-])C1</smiles>

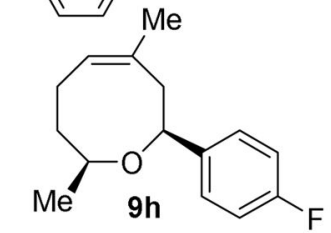<smiles>CC1=CCCC(C)OC(c2ccc(C(F)(F)F)cc2)C1</smiles><smiles>CC1=CCC[C@H](C)O[C@@H](c2ccc(Cl)cc2)C1</smiles><smiles>CC1=CCC[C@@H](C)O[C@H](CCc2ccccc2)C1</smiles><smiles>CC1CCC=C([N+](=O)[O-])CC(COCc2ccccc2)O1</smiles><smiles>CC1=CCCC(C)OC(c2cccc([N+](=O)[O-])c2)C1</smiles><smiles>C/C=C\CC1CC(C)=CCCC(C)O1</smiles><smiles>CC1=CCC[C@@H](C)O[C@H](c2ccc(F)c([N+](=O)[O-])c2)C1</smiles>

Figure 2.

Structure of major isomer 


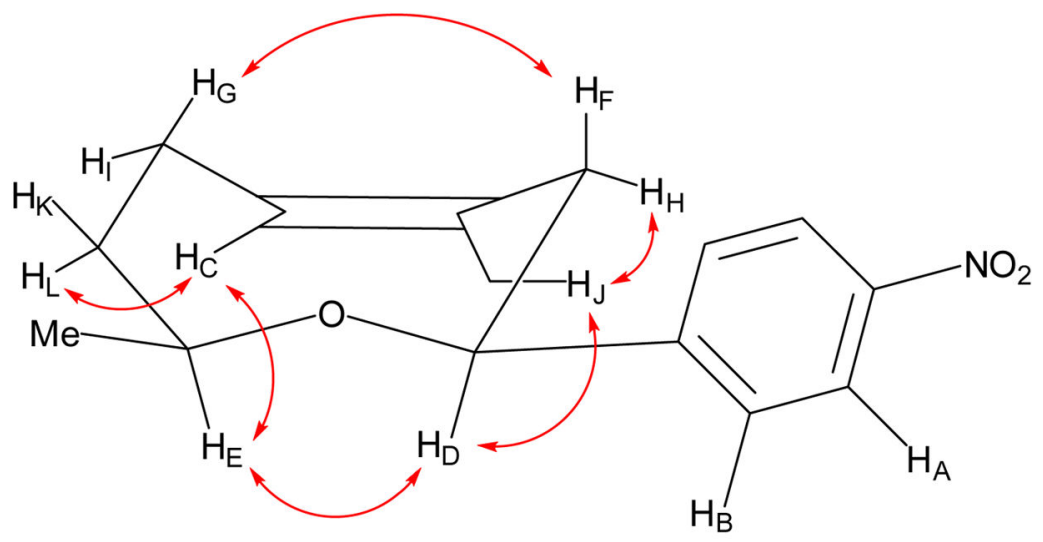

Figure 3.

${ }^{1} \mathrm{H}-\mathrm{NMR}$ NOESY of compound 9a 

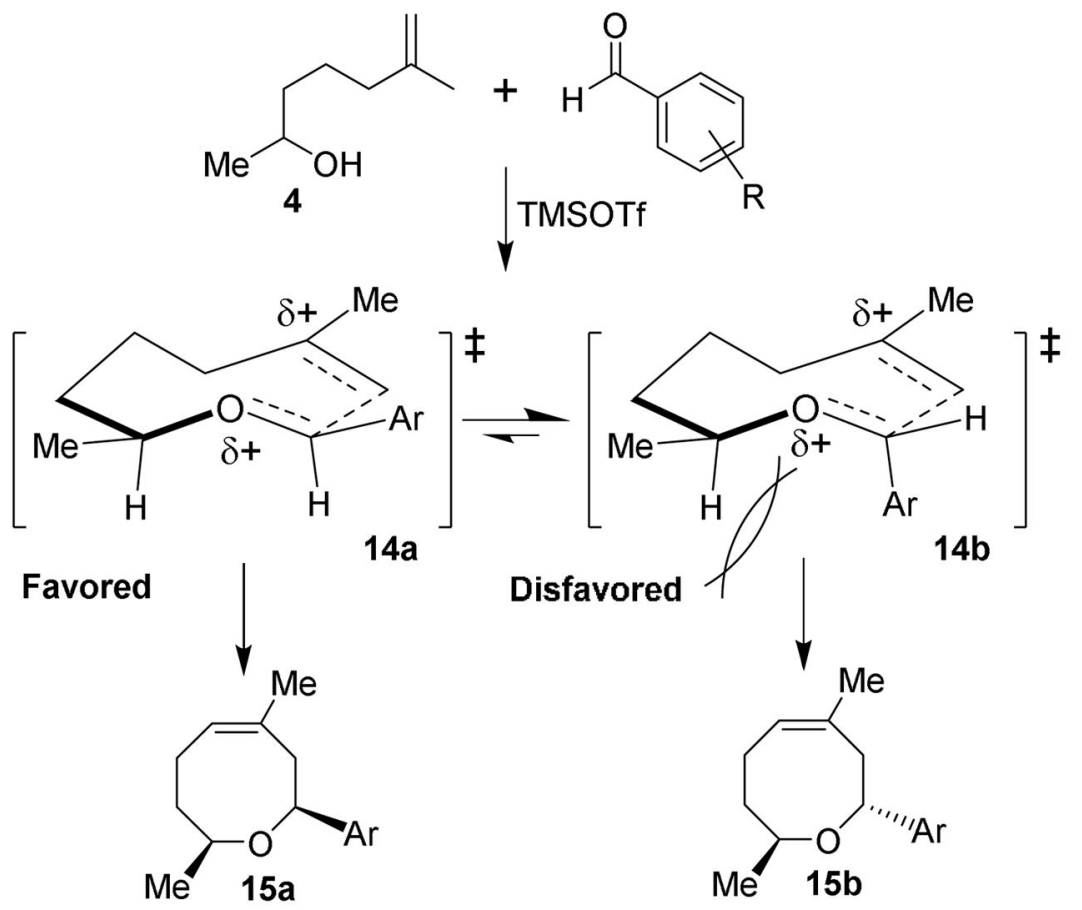

Figure 4.

Stereochemical analysis for cis-oxocene products 
<smiles>C=C(C)CCCC(C)O</smiles><smiles>CC1=CC(COCc2ccccc2)=C(C)CCC1</smiles><smiles>CC1=CCCC(C)OC(COc2ccccc2)C1</smiles>

Scheme 1.

Formation of THP and oxocene products 
<smiles>C=C(C)[C@H]1CC[C@@H](C)O[C@H]1c1ccc([N+](=O)[O-])cc1</smiles>

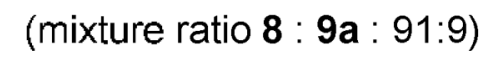

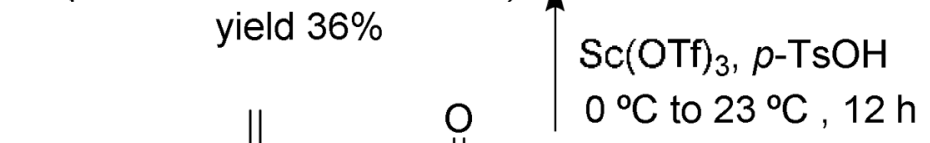<smiles>C=C([CH2+])CCCC(C)O</smiles>

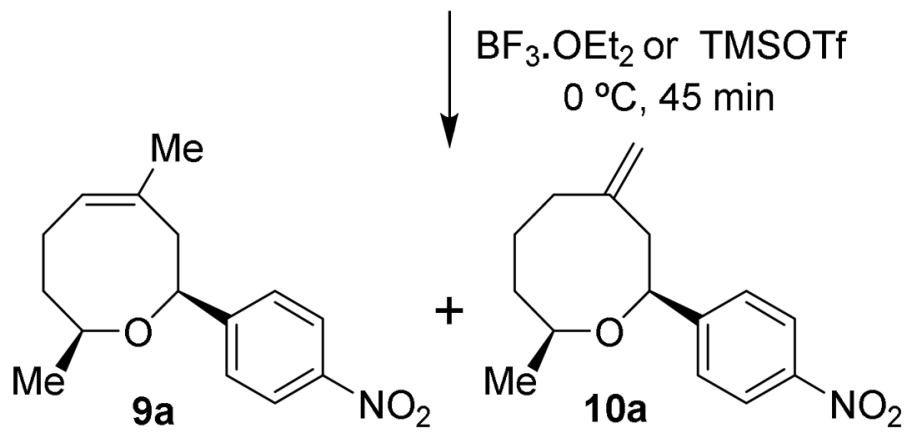

Scheme 2.

Formation of oxocene products 
<smiles>C=C1CCC[C@@H](C)O[C@@H](c2cccc([N+](=O)[O-])c2)C1</smiles>

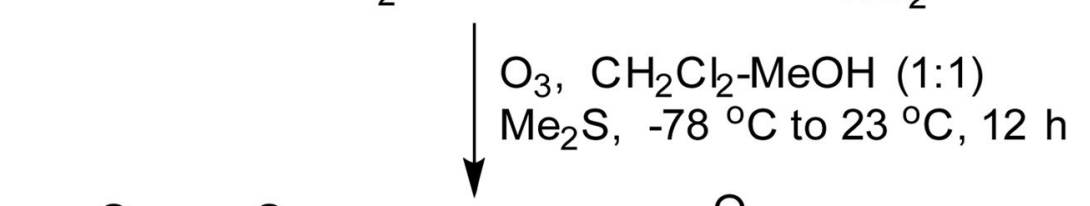<smiles>CC(=O)CC[C@H](C)O[C@@H](CC(C)=O)c1cccc([N+](=O)[O-])c1</smiles><smiles>O=[123I]</smiles>

$+$<smiles>C[C@H]1CCCC(=O)C[C@@H](c2cccc([N+](=O)[O-])c2)O1</smiles>

1. Separation

2. $\mathrm{Ph}_{3} \mathrm{P}=\mathrm{CH}_{2}$, THF

$\checkmark-78^{\circ} \mathrm{C}$ to $0^{\circ} \mathrm{C}, 5 \mathrm{~h}$<smiles>C=C1CCC[C@@H](C)O[C@H](c2cccc([N+](=O)[O-])c2)C1</smiles>

Scheme 3.

Preparation of exo-oxocene isomer $10 f$ 


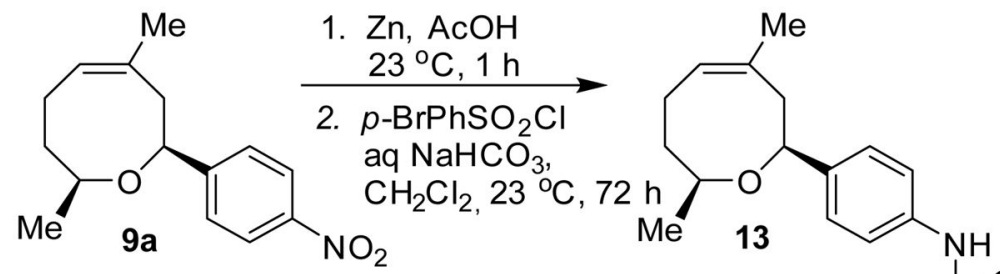

13

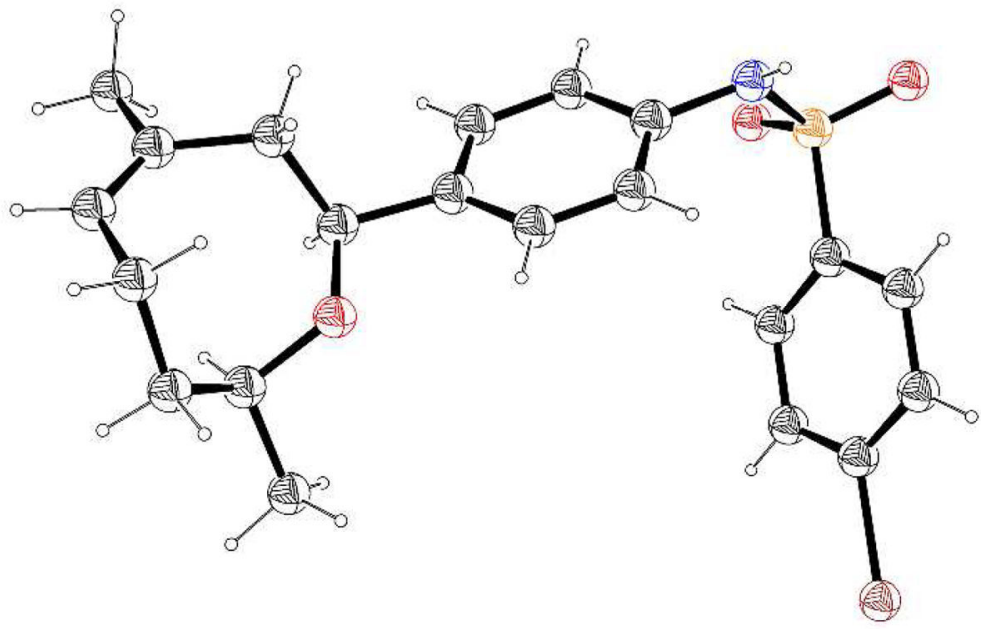

Scheme 4.

Synthesis and X-ray structure of $\mathbf{1 3}^{\mathrm{a}}$

${ }^{\mathrm{a}}$ White $=$ hydrogen, black $=$ carbon, red $=$ oxygen, blue $=$ nitrogen, yellow $=$ sulfur, brown $=$ bromine 

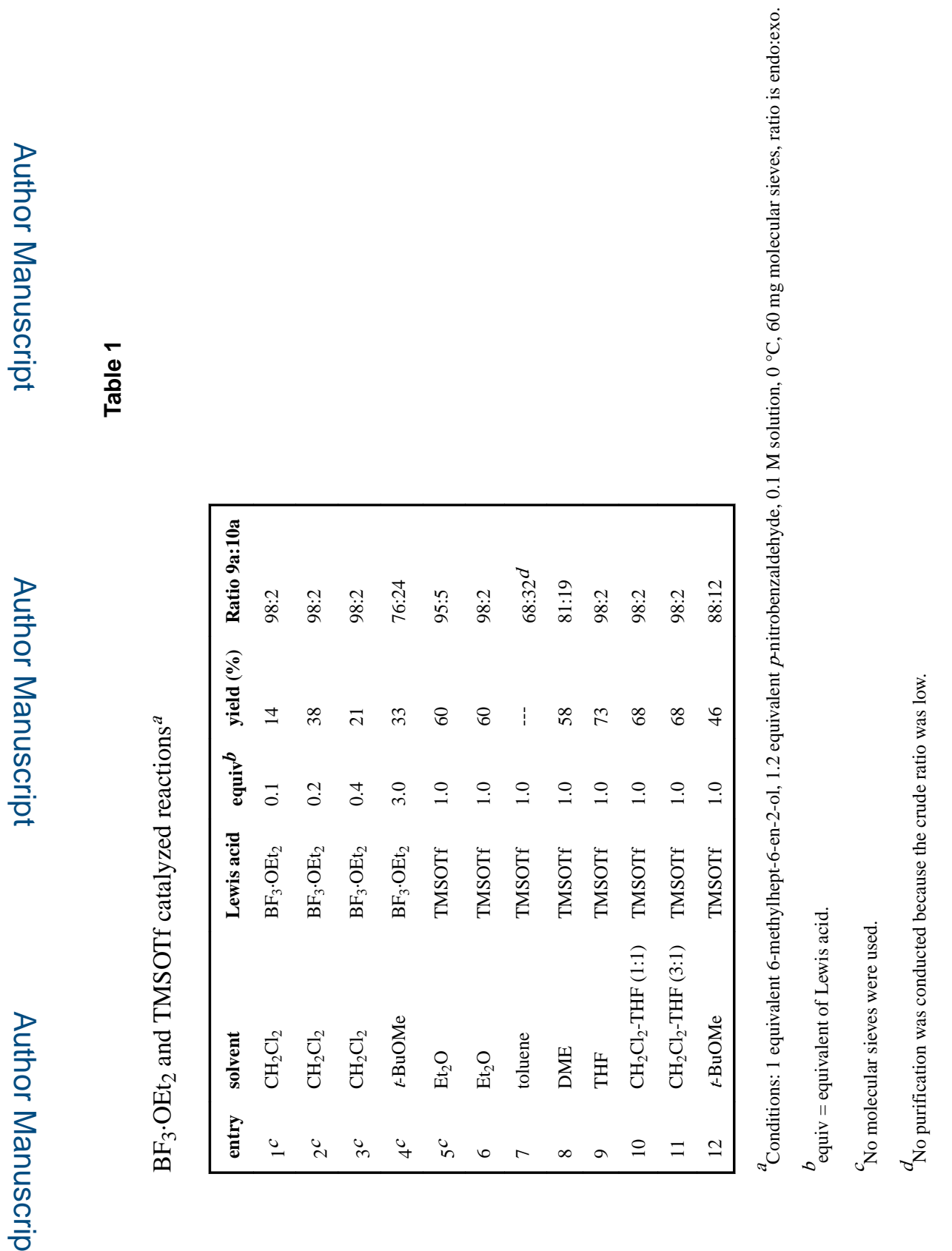

Org Lett. Author manuscript; available in PMC 2017 February 20. 


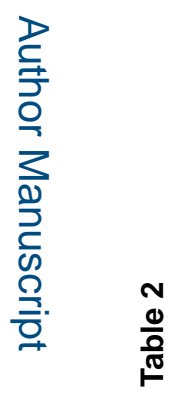

로을

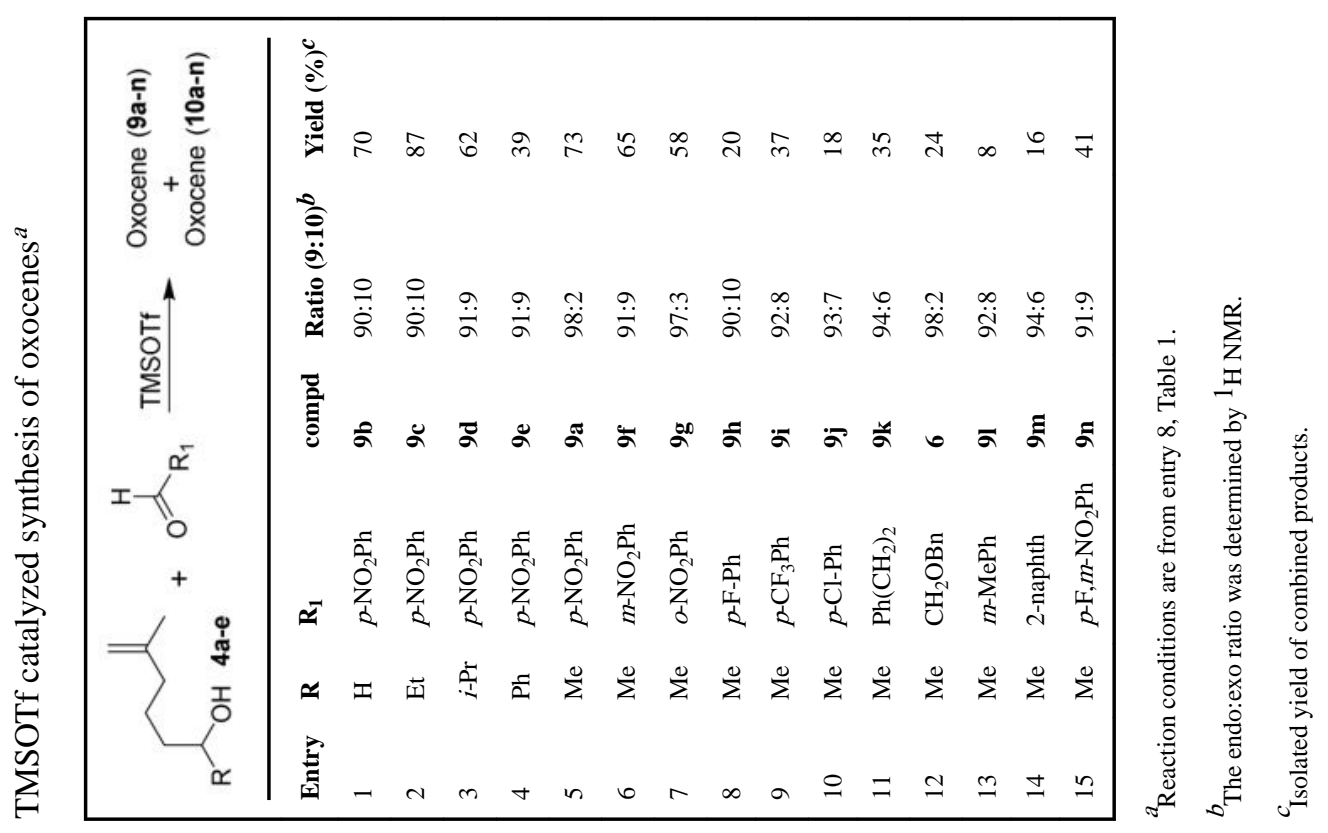

Org Lett. Author manuscript; available in PMC 2017 February 20. 